\title{
Research Paper: Prevalence of Work-related Musculoskeletal Disorders and Injuries in Occupational and Physical Therapists and Its Comparison
}

\author{
Himan Nazari', Hossein Hosseini Mahjoob² ${ }^{2}$ Leili Tapak$^{1}$, Saideh Sadat Mortazavi ${ }^{\star *}$
}

1. Department of Occupational Therapy, Faculty of Rehabilitation, Hamadan University of Medical Sciences, Hamadan, Iran.

2. Department of Biostatistics and Epidemiology, Faculty of Health, Hamadan University of Medical Sciences, Hamadan, Iran.

\begin{tabular}{|l|l|l|l}
\hline $\begin{array}{l}\text { Use vour device toscan } \\
\text { and read the artico online }\end{array}$ & $\begin{array}{l}\text { Crtation: Nazari H, Hossaini Mahjoob H, Tapak L, Mortazavi SS. Prevalence of Work-related Musculoskeletal Disorders and } \\
\text { Injuries in Occupational and Physical Therapists and Its Comparison. Iranian Rehabilitation Journal. 2017; 15(1):31-36. https:// } \\
\text { doi.org/10.18869/nrip.irj.15.1.31 }\end{array}$ \\
dol: $:$ https://doi.org/10.18869/nrip.irj.15.1.31
\end{tabular}

Article info:

Received: 30 Nov. 2016

Accepted: 01 Feb. 2017

\section{Keywords:}

Musculoskeletal disorder,

Work-related injury,

Occupational therapist,

Physiotherapist

\section{ABSTRACT}

Objectives: Musculoskeletal disorders (MSD) are the most prevalent occupational diseases that are serious, fundamental and costly in nature.

Methods: This analytical descriptive study included 45 individuals of occupational and physiotherapy community in Hamedan, Nahavand and Malayer cities of Iran.

The standardized Nordic questionnaire was used to collect data. Data analysis was done by SPSS software, chi-square test, T-test and Kay Score tests.

Results: Study results revealed the prevalence of MSD accounting for $65.9 \%(n=27)$ of the study population who at least had one part of their body infected. In a 12 months study period, the disorder symptoms were seen in wrist (34.1\%), lumbar (31.7\%), knee (29.3\%), neck (26.8\%), shoulder (19.5\%), and back (17\%). A significant relation was seen between the symptoms of the wrist and hand. This was more common among occupational therapists. The results also showed that the disorders in occupational therapists affected all the limbs, except the neck. In addition, the females were more susceptible to the disorders compared to the males.

Discussion: This study confirmed the rate of prevalence of work-related musculoskeletal disorders and injuries in occupational and physical therapists, with wrist and lumbar being the most affected. The promotion of therapist's knowledge about MSD and following ergonomic principles and new approaches in the treatment may lower or prevent MSD.

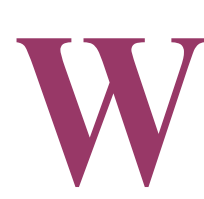

\section{Introduction}

ork-related injuries and Musculoskeletal Disorders (MSD) generally occur in people doing jobs. This is because of their poor physical postures that can lead to many ill consequences, such as job loss, job restrictions, fatigue, or job change [1-4]. The most common work-related injuries are the MSD, which are the main source of downtime and related costs in our country [5].

* Corresponding Author:

Saideh Sadat Mortazavi, MSc.

Address: Department of Occupational Therapy, Faculty of Rehabilitation, Hamadan University of Medical Sciences, Hamadan, Iran

Tel: +98 (912) 5176104

E-mail:s.mortazavi.ot@gmail.com 
Injuries and diseases affect $78 \%$ of the total population. However, only $14 \%$ of them get doctor appointments and $15 \%$ get hospital admissions. According to medical statistics, $62 \%$ of people with MSD suffer from restrictive movement $[6,7]$.

Several factors lead to the occurrence of such disorders. One of these factors is repetitive movement. In some jobs, such as occupational and physical therapy, because of the risk factors, such as activity repetition, force, awkward postures and lack of leisure time, there is an increased risk of work-related injuries [5, 8]. Recent evidence suggests that the annual incidence of these diseases in occupational therapists and physiotherapists is on the rise. For example, in the US, the incidence of these work-related disorders in the case of therapists increased from $2 \%$ to $10 \%$ in 2004 , from $5 \%$ to $10 \%$ in 2005 , and from $5 \%$ to $13 \%$ in 2006 [1]. Researchers suggest The therapist who goes for therapy sessions during an 8-hour day work on 15 to 20 patients experiences more risk of work damage [9].

The purpose of this study was to examine the prevalence of MSD in occupational therapists and physiotherapists along with the determination of the risk level for them. The findings will help improve their working conditions and prevent work-related disorders.

\section{Methods}

This is a cross-sectional study that was conducted during the period 2013-2014 to examine the rate of incidence of MSD among occupational and physical therapists and comparing the symptoms seen in the therapists. Therefore, all the participants were occupational and physical therapists who were short listed from the Hamedan, Malayer and Nahavand cities of Iran through a numeration method. Demographic characteristics of the study population $(\mathrm{N}=41)$ are presented in Table 1 . The study aim and the method used were explained to the therapists to participate consciously or leave the test if they did not want to participate. The exclusion criteria included less than one year of work experience, incomplete questionnaires, and congenital or accidental physical disabilities.

All of them were asked to fill a Nordic musculoskeletal questionnaire, which is one of the most common questionnaires about symptoms of MSD from the work presented by Kuorinka and his colleagues in Occupational Health Institutes of Scandinavian countries [10]. This questionnaire can be used as a suitable standard to gather necessary data and information about MSD and disease epidemiology and related work MSD. The questionnaire included two sections:

1) The first section: It had 18 questions that were further divided into two parts: the first part included nine questions to review the participant's personal information and demography (height, weight, prior acute injuries, surgery, relevant systemic diseases, alcohol intake, tobacco use, sports, and hobbies). Subjects reporting musculoskeletal symptoms in the year preceding the interview were asked additional questions, such as year of onset, symptom frequency, and duration within the past year. In the second part, there were nine questions to examine the participant's information about their (year) work experience, working hour, and job circulation.

2) The second section: The Nordic questionnaires consisted of 27 binary choice questions (yes or no). There were three questions in the questionnaire, which also had three separate parts that examined the MSD in nine body areas (neck, shoulders, wrist/hands, upper back, low back, hips/thighs, knees, ankles/feet) at different times during the previous one year of the study period.

The first was "had some troubles or pain in the last 12 months", the second was "in the last 12 months felt some limitation caused by work in the daily activities", and the third was "had some troubles or pain in the last 7 days".

All statistical analyses were performed with the SPSS software (Version, company, country). In order to examine the relationship between the gender, lateral advantages and MSD, the chi-square test had been applied. For deriving the relationship between age, weight, weekly working hours, yearly work experiences and MSD, the T-test was used.

\section{Results}

Forty-five occupational and physical therapists have been included in the study; of them, four were excluded from the study because of less than one year of work experience or incomplete questionnaires.

From 41 occupational and physical therapists, $23(56.1 \%)$ were male and $18(43.9 \%)$ were female; 17 were occupational therapists and $24(58.5 \%)$ were physical therapists; $33(80.48 \%)$ were married and 8 (19.52\%) were single; and 36 were right handed and 5 were left handed. None of the participants were smokers.

The result showed no significant relationships between age, height, weight, and gender with the rate of incidence of musculoskeletal disorders $(\mathrm{P}<0.05)$ (Table 2$)$. 
Table 1. Demographic characteristics of the study population $(\mathrm{N}=41)$

\begin{tabular}{ccccc}
\hline Variable & Mean & Maximum & Minimum & SD \\
\hline Age $(\mathrm{y})$ & 36.49 & 51 & 24 & 7.406 \\
Weight $(\mathrm{kg})$ & 70.71 & 95 & 52 & 11.358 \\
$\begin{array}{c}\text { Height }(\mathrm{cm}) \\
\text { Hours per week }\end{array}$ & 171.15 & 187 & 151 & 8.999 \\
Work experience (y) & 46.37 & 72 & 14 & 12.876 \\
\hline
\end{tabular}

SD: Standard Deviation

Iranian Rehabilitation Journal

Table 2. Relationship between age, height, weight, gender, and musculoskeletal disorders

\begin{tabular}{ll}
\hline Variable & P \\
\hline Age & 0.151 \\
Weight & 0.542 \\
Height & 0.794 \\
Gender & 0.925 \\
\hline
\end{tabular}

Iranian Rehabilitation Journal

Table 3. Prevalence of disorder in different body parts and limitations in activities of daily living among occupational and physical therapists

\begin{tabular}{|c|c|c|c|c|c|c|}
\hline \multirow[b]{2}{*}{ Variables } & \multicolumn{2}{|c|}{$\begin{array}{l}\text { Do You Have a Problem } \\
\text { During the Past } 12 \text { Months, } \\
\text { Such as Pain, Discomfort and } \\
\text { Numbness in the Extremities? }\end{array}$} & \multicolumn{2}{|c|}{$\begin{array}{c}\text { Do You Have a Problem Dur- } \\
\text { ing the Last } 7 \text { Days as Pain, } \\
\text { Discomfort and Numbness in } \\
\text { the Limbs? }\end{array}$} & \multicolumn{2}{|c|}{$\begin{array}{l}\text { Are You Unable to Do Every- } \\
\text { day Activities, Such as Occu- } \\
\text { pational Activities, Recreation } \\
\text { and Housework During the } \\
\text { Last } 12 \text { Months Due to MSD? }\end{array}$} \\
\hline & $\begin{array}{c}\text { Yes } \\
\text { Number(\%) }\end{array}$ & $\begin{array}{c}\text { No } \\
\text { Number(\%) }\end{array}$ & $\begin{array}{c}\text { Yes } \\
\text { Number(\%) }\end{array}$ & $\begin{array}{c}\text { No } \\
\text { Number(\%) }\end{array}$ & $\begin{array}{c}\text { Yes } \\
\text { Number(\%) }\end{array}$ & $\begin{array}{c}\text { No } \\
\text { Number(\%) }\end{array}$ \\
\hline Neck & $11(26.8)$ & $30(73.2)$ & $4(9.8)$ & $30(73.2)$ & $6(14.6)$ & $35(85.4)$ \\
\hline One or both shoulders & $8(19.5)$ & $33(80.5)$ & $2(4.9)$ & $33(80.5)$ & $2(4.9)$ & 39(95.1) \\
\hline One or both elbows & $5(12.2)$ & $36(87.8)$ & 0 & $36(87.8)$ & $1(2.4)$ & 40(97.6) \\
\hline Wrists/Hands & $14(34.1)$ & $27(65.9)$ & $4(9.8)$ & $27(65.9)$ & $4(9.8)$ & $37(90.2)$ \\
\hline Upper back & $7(17.1)$ & $34(82.9)$ & $2(4.8)$ & $34(82.9)$ & $1(2.4)$ & $40(97.8)$ \\
\hline Low back & $13(31.7)$ & $28(68.3)$ & $7(17.1)$ & $28(68.3)$ & $6(14.6)$ & $35(85.4)$ \\
\hline One or both hips & $3(7.3)$ & $38(92.7)$ & $2(4.9)$ & $38(92.7)$ & $1(2.4)$ & 40(97.6) \\
\hline One or both knees & $12(29.3)$ & $29(70.7)$ & $6(14.6)$ & $29(70.7)$ & $5(12.2)$ & $36(87.8)$ \\
\hline One or both ankles & $3(7.3)$ & $38(92.7)$ & 0 & $38(92.7)$ & $2(4.9)$ & $39(95.1)$ \\
\hline Total & $27(65.9)$ & $14(34.1)$ & $15(36.6)$ & $14(34.1)$ & $15(36.6)$ & $26(63.4)$ \\
\hline
\end{tabular}

Note: MSD: Musculoskeletal Disorders 
Table 4. The difference between occupational therapists and physiotherapists extremity involvement in the past 12 months

\begin{tabular}{ccccccccc}
\hline Jobs & Ankle (n) & Knee (n) & Hip (n) & Lumbar (n) & Wrist (n) & Elbow (n) & Shoulder (n) & Neck (n) \\
\hline $\begin{array}{c}\text { Occupational } \\
\text { therapists }\end{array}$ & 2 & 3 & 7 & 3 & 10 & 4 & 4 & 4 \\
\begin{tabular}{c} 
Physiotherapists \\
\hline
\end{tabular} & 1 & 0 & 6 & 4 & 4 & 1 & 4 & 7 \\
\hline
\end{tabular}

It also showed that the relationship between weekly working hours and work experience in the present station (year) was not significant, yielding an amount of possibility $(\mathrm{P})$ for both variables, 0.065 that is really close to $\mathrm{P}<0.05$. The participants also reported absence of medical history related to MSD in the past or right before the work. The incidence of MSD based on body parts indicated that the majority of disorders were related to hand/wrist, affecting $10(58.8 \%)$ and 4 people $(16.6 \%)$ in occupational and physical therapies, respectively.

The results showed that in last 12 months, the MSD symptoms were commonly seen in the wrist and hand, back, knees and neck, and in last 7 days, they were mostly seen in the waist and knees. During this period, the major limitations caused by MSD in performing the daily activities were due to the immobility in the neck, back, knees, and wrist. Table 3 shows the frequency of having MSD in nine different areas of the body and the limitation in performing the daily life activities.

Out of 17 occupational and 24 physical therapists who were included in the study, 13(76.4\%) and 14 (58.3\%) of them, respectively, experienced symptoms of MSD. The result showed that the occupational therapists experienced more serious problems than the physical therapists, and in addition to this, the females suffered more than the male.

Furthermore, the rate of incidence of MSD in therapists at the wrists and hands has been significant in last 12 months, and this was more in occupational therapists, affecting the limbs except the neck.

\section{Discussion}

According to view point of health organizations, health is not only having no disease but having great physical, mental and social comfort. Health complications emerging out of the professional lifestyle has led to a decrease in work efficiency and low job satisfaction [11]. The present study showed that the incidence rate of MSD among occupational and physical therapists is about $65.9 \%$. Most of the therapists who have less than one year of work experience and the students (seniors) who were not part of our study population also reported the symptoms of MSDs. This level of high incidence was in the same direction with the study performed by Darragh and Nordin in Ohayo Public University of the USA and Malaysia, respectively $[1,9]$. The rate incidence of MSD among occupational therapists was $76.4 \%$ and among physical therapists was $58.3 \%$. The high incidence rate among the occupational therapists might be because they performed technical jobs manually. Table 4 shows the rate of affected areas based on the limbs.

Moreover, most of the patients of occupational therapists in Iran are neurologic (high spastic) and suffer from cerebral palsy, CVA, and other chronic diseases, whereas physical therapist's jobs are highly focused on related tools and machines and orthopedic patients. Also, the therapy sessions demand the occupational therapists to put their patients in different positions, which force them to get extremely connected with their patients. Such repetitive actions led to more symptoms of MSDs. The present study also showed that the disorders were mostly in hand/wrist (34.1\%), back (31.7\%), knee (29.3\%), and neck $(26.8 \%)$ and that has been proved by Bork et al.'s study in Lava university I in the year 1996 [12].

Additionally, our study results were in the same direction with Nordin's study, which showed the difference in MSD symptoms between male and female medics that was not taken into consideration, although it was about $1.5 \%$ more in females [9]. Moreover, the results showed that inappropriate body mass, repetitive actions, working time period, and positioning while working were effective in MSD, which are unanimous with Cromie and Nordin et al in Australia and Malaysia, respectively [5, 8, $9,13]$. The results were also similar to King et al.'s study, which showed that more experienced therapists reported increased symptoms and similar disorders, which led to low quality job and more sick leaves [2]. However, apparently the relationship between MSD and weekly working hours and experiences was not significant [9]. It should be noted that the physical profession medics like CPs, adults orthopedists and neurologists have shown more disorder symptoms and have mentioned their dissatisfactions during interviews or queries than mentalists and psychologists [14]. 


\section{Conclusion}

The present study showed that 24 of the therapists (65.9\%) reported suffering from at least one type of MSD. The disorders were more common in occupational therapists than physical therapists; however, the gender was not effective. Most of the disorders were reported by occupational therapists, especially in their hands and wrists during the last 12 months. Considering the enormous difference between the rate of incidence among occupational therapists and physical therapists, we suggest occupational therapists should use other approaches plus their manual practices and follow ergonomic basis while handling and transferring their patients.

\section{Acknowledgments}

This paper is based on a student work, which was done under financial support of Hamedan University of Medical Sciences student work.

\section{Conflict of Interest}

The authors declared no conflicts of interest. co factory in 2013. Iranian Journal of Health Sciences. 2013 1(2):89-94. doi: 10.18869/acadpub.jhs.1.2.89

[8] Gatchel RJ, Schultz IZ. Handbook of musculoskeletal pain and disability disorders in the workplace. New York: Springer; 2014.

[9] Nordin NZ, Leonard JH, Chuen Thye NG. Work-related injuries among physiotherapists in public hospitals: A Southeast Asian picture. Clinics. 2011; 66(3):373-378. PMCID: PMC3071994

[10] Kuorinka I, Jonsson B, Kilbom A, Vinterberg H, BieringSørensen F, Andersson G, et al. Standardised Nordic questionnaires for the analysis of musculoskeletal symptoms. Applied Ergonomics. 1987; 18(3):233-7. doi: 10.1016/00036870(87)90010-x

[11] Puriene A, Aleksejuniene J, Petrauskiene J, Balciuniene I, Janulyte V. Self-reported occupational health issues among Lithuanian dentists. Industrial Health. 2008; 46(4):369-74. doi: 10.2486/indhealth.46.369

[12] Aranyavalai T. Survey of work-related musculoskeletal disorders among Thai physical therapists in Bangkok and perimeter areas [PhD thesis]. Bangkok: Mahidol University; 2011.

[13] Cromie JE, Robertson VJ, Best MO. Work-related musculoskeletal disorders and the culture of physical therapy. Physical therapy. 2002; 82(5):459-472. PMID: 11991799

[14] Glover W, McGregor A, Sullivan C, Hague J. Work-related musculoskeletal disorders affecting members of the chartered Society of physiotherapy. Physiotherapy. 2005; 91(3):138-47. doi: 10.1016/j.physio.2005.06.001

\section{References}

[1] Darragh AR, Huddleston W, King P. Work-related musculoskeletal injuries and disorders among occupational and physical therapists. American Journal of Occupational Therapy. 2009; 63(3):351-62. doi: 10.5014/ajot.63.3.351

[2] King P, Huddleston W, Darragh AR. Work-related musculoskeletal disorders and injuries: Differences among older and younger occupational and physical therapists. Journal of Occupational Rehabilitation. 2009; 19(3):274-83. doi: 10.1007/ s10926-009-9184-1

[3] Salik Y, Özcan A. Work-related musculoskeletal disorders : A survey of physical therapists in Izmir-Turkey. BMC Musculoskeletal Disorders. 2004; 5(1):27. doi: 10.1186/1471-24745-27

[4] Balogun JA, Titiloye V, Balogun A, Oyeyemi A, Katz J. Prevalence and determinants of burnout among physical and occupational therapists. Journal of Allied Health. 2002; 31(3):131-139. PMID: 12227263

[5] Habibi EA, Karimi S, Hasanzadeh A. [Evaluation of ergonomic risk factors by OCRA method in assembly industry (Persian)]. Iran Occupational Health Journal. 2008; 5(1-2):70-76.

[6] Sadri G. A Model of bus drivers disease: Risk factors and bus accidents. Iranian Journal of Medical Sciences. 2002; 27(1):39-41.

[7] Etemadinezhad S, Ranjbar F, Gorji M. Posture analysis by OWAS method and prevalence of musculoskeletal disorders using Nordic questionnaire among workers of Sourak tobac- 
